\title{
A cluster randomised controlled trial of a telephone-based intervention targeting the home food environment of preschoolers (The Healthy Habits Trial): the effect on parent fruit and vegetable consumption
}

\author{
Rebecca Wyse ${ }^{1,4^{*}}$, Karen J Campbell ${ }^{2}$, Leah Brennan ${ }^{3}$ and Luke Wolfenden ${ }^{1,4,5}$
}

\begin{abstract}
Background: The home food environment is an important setting for the development of dietary patterns in childhood. Interventions that support parents to modify the home food environment for their children, however, may also improve parent diet. The purpose of this study was to assess the impact of a telephone-based intervention targeting the home food environment of preschool children on the fruit and vegetable consumption of parents.

Methods: In 2010, 394 parents of 3-5 year-old children from 30 preschools in the Hunter region of Australia were recruited to this cluster randomised controlled trial and were randomly assigned to an intervention or control group. Intervention group parents received four weekly 30-minute telephone calls and written resources. The scripted calls focused on; fruit and vegetable availability and accessibility, parental role-modelling, and supportive home food routines. Two items from the Australian National Nutrition Survey were used to assess the average number of serves of fruit and vegetables consumed each day by parents at baseline, and 2-, 6-, 12-, and 18-months later, using generalised estimating equations (adjusted for baseline values and clustering by preschool) and an intention-to-treat-approach.
\end{abstract}

Results: At each follow-up, vegetable consumption among intervention parents significantly exceeded that of controls. At 2-months the difference was 0.71 serves ( $95 \% \mathrm{Cl}: 0.58-0.85, \mathrm{p}<0.0001)$, and at 18 -months the difference was 0.36 serves ( $95 \% \mathrm{Cl}: 0.10-0.61, p=0.0067)$. Fruit consumption among intervention parents was found to significantly exceed consumption of control parents at the 2-,12- and 18-month follow-up, with the difference at 2-months being 0.26 serves (95\% Cl: $0.12-0.40, p=0.0003)$, and 0.26 serves maintained at 18 -months, (95\% Cl: $0.10-0.43, p=0.0015)$.

Conclusions: A four-contact telephone-based intervention that focuses on changing characteristics of preschoolers' home food environment can increase parents' fruit and vegetable consumption.

(ANZCTR12609000820202)

Keywords: Fruit, Vegetable, Randomised controlled trial, Intervention, Telephone, Family, Home food environment, Preschool, Child

\footnotetext{
* Correspondence: rebecca.wyse@hnehealth.nsw.gov.au

'School of Medicine and Public Health, University of Newcastle, Newcastle, NSW, Australia

${ }^{4}$ Hunter Medical Research Institute (HMRI), Newcastle, NSW, Australia

Full list of author information is available at the end of the article
} 


\section{Background}

From a young age many children fail to meet minimum dietary guidelines for fruit and vegetable consumption $[1,2]$. Dietary patterns established in childhood track into adulthood [3], and insufficient childhood consumption of fruit and vegetables is linked to an increased risk of chronic disease in adults $[4,5]$. As such increasing the fruit and vegetable consumption of children represents a global health priority [6]. Ecological models suggest that the home food environment is an important setting for the development of dietary patterns in childhood [7]. Parents are gatekeepers to the home food environment $[7,8]$ through: making foods available and accessible to children [9]: role modelling [10]; and establishing eating rules and encouraging specific eating behaviours [11]. In addition, parents' own behaviours may be modified by the environment they establish for their children. As such, interventions that focus on changing the home food environment may impact the dietary patterns of parents as well as their children.

A recent systematic review of interventions to increase fruit and vegetable consumption among children aged $0-5$ years [12] identified only one study attempting to change the home food environment. A four-contact, home-visiting program increased parent fruit and vegetable consumption, but did not change child consumption [13]. Since the review, the Infant Feeding Activity and Nutrition Trial (InFANT) showed that a parent intervention to improve infant diet, which also included strategies targeting some aspects of the home food environment, improved maternal diet quality [14]. The intervention was delivered via parenting groups over the first 18 months of the infants' life, and focused on teaching parenting skills to support the development of positive diet behaviours in infancy. Furthermore, the Healthy Habits trial, demonstrated that a four-contact telephone-based intervention with parents that focused on creating a supportive home food environment could increase fruit and vegetable consumption among 3-5 year-old children [15]. After 12 months, the combined fruit and vegetable consumption of intervention children was significantly greater than consumption of control children [16]. However, after 18 months the difference between groups was no longer significant [16]. This intervention supported parents to make changes to their home food environment associated with higher fruit and vegetable consumption in children; increasing the availability and accessibility of fruit and vegetables in the home, increasing parental role-modelling, and introducing supportive home food routines [17-19].

There is a well-established literature regarding effective interventions to increase adult fruit and vegetable consumption, with systematic reviews finding evidence in favour of behavioural interventions [20,21], and specifically those utilising face-to-face nutrition education or counselling [22]. A review of environmental approaches to encourage healthy eating highlighted the potential for home-based environmental interventions, however the authors concluded there was a paucity of such interventions [23]. The current study attempts to address this gap in the literature and investigate the efficacy of a home food environment intervention on the dietary behaviours of parents. Specifically, this paper describes the changes in the average daily serves of fruit and of vegetables consumed by parents, at 2-, 6-12- and 18-months, the secondary outcomes of the Healthy Habits trial. It was hypothesised that consumption among intervention parents would exceed that of controls at each follow-up time point.

\section{Methods}

The trial was registered with the Australian New Zealand Clinical Trials Registry on Sept 212009 (ANZCTR12609000820202) and approved by the Hunter New England Health Human Research Ethics Committee. A detailed description of the methods employed in this cluster randomised controlled trial have been published elsewhere and are described briefly below [24]. Parents of 3-5 year-old children were recruited to the trial from 30 preschools in the Hunter region of NSW, Australia. Parents were allocated to an intervention (telephone support) or control condition (written information) using block randomisation in a 1:1 ratio based on the preschool of recruitment. Preschool randomisation was conducted by an independent statistician using a random number function in Microsoft Excel. Following collection of baseline data, parents were notified of their group allocation by letter.

\section{Intervention}

The intervention, described in greater detail elsewhere [24], was developed in conjunction with a multi-disciplinary advisory group that included accredited practicing dietitians, psychologists specialising in parenting, and health promotion professionals. The intervention was conceptually guided by the model of family-based intervention used in the treatment and prevention of childhood obesity, as proposed by Golan and colleagues [25]. The model is grounded in socio-ecological theory and attempts to introduce new familial norms regarding healthy eating. The intervention was previously piloted in a small sample which demonstrated effectiveness, feasibility of delivery, and acceptability to parents [26]. The intervention was delivered through a series of four weekly 30-minute telephone calls. The calls were scripted and delivered by experienced telephone interviewers. The script content and homework activities were tailored based on parents' responses and focused on; fruit and vegetable availability and accessibility, parental role-modelling, and supportive 
home food routines (e.g. children having set meal and snack times). Behaviour change techniques such as goal setting and role-modelling [27] were built into the script. The intervention also consisted of written resources. Intervention parents received the 'Healthy Budget Bites' cookbook, which was developed locally and was specifically designed to encourage healthy eating through the provision of simple, inexpensive recipes [28]. The Healthy Habits guidebook was designed to accompany each of the calls. It provided a summary of the content of each call, as well as factsheets with more detail about each of the included topics. There was dedicated space in the guidebook where participants were encouraged to record their goals and activities for each week. Intervention parents also received a pad of weekly meal planner templates. The intervention was delivered between April and December 2010. Approximately $6 \%$ of all intervention calls were monitored by members of the research team, with results indicating that $97 \%$ of key content areas of the script were covered, and in $80 \%$ of calls the telephone interviewers "rarely" deviated from the script [15]. Of the intervention parents, 181 (87\%) completed all intervention calls [15], and the median number of call attempts per completed intervention call was three attempts for the Week 1 call, and two attempts for the calls in Weeks 2,3 \& 4 .

\section{Control}

Parents were mailed printed information about Australian dietary guidelines [29]. They received no further contact until the follow-up assessments.

\section{Data collection \& measures}

Telephone interviewers, blind to group allocation, collected data at baseline (from April to October 2010) and 2-, 6-, 12-, and 18-months later. Items from the Australian National Nutrition Survey [30] were used to assess the average daily serves of fruit and vegetables consumed by parents. (How many serves of vegetables do you usually eat each day? One adult serve is a $1 / 2$ cup of cooked vegetables or 1 cup of salad vegetables. How many serves of fruit do you usually eat each day? An adult serve is 1 medium piece or 2 small pieces of fruit or 1 cup of diced pieces). A study of 1,598 Australian adults found these items were significantly associated with biomarkers of fruit and vegetable intake (alpha- and beta-carotene and red-cell folate) [31].

\section{Analysis}

At each follow-up, generalised estimating equations were used to compare parents' mean daily fruit and vegetable serves between groups. Fruit and vegetable outcomes were analysed separately. The analyses were adjusted for clustering by preschool and baseline values (i.e. baseline daily serves of vegetables and fruits respectively). An intention- to-treat approach was utilised, whereby participants were analysed based on the group to which they were originally allocated. All available data was used in the initial analysis. A sensitivity analysis was also conducted whereby baseline values were substituted for missing data (Baseline Observation Carried Forward). The trial was powered based upon the primary outcome (children's fruit and vegetable consumption). However, using the same assumptions it was calculated that the sample would allow a between group detectable difference of 0.33 and 0.43 daily serves of fruit and vegetables respectively, with $80 \%$ power at the 0.05 significance level, after 18 months.

\section{Results}

A description of the study response rates and attrition is described in detail elsewhere $[15,16]$. Of the 394 parents recruited into the study $78 \%$ of those allocated to the intervention group and $88 \%$ of those allocated to the control group provided 18-month follow-up data (Figure 1).

Most parents who completed the baseline survey were female (96\%), university educated (47\%) with a household income over AUS $\$ 100,000$ per year (41\%); the average age was 35.4 years $(\mathrm{SD}=5.4)$, and parents had an average of 2.3 children under 16 years $(\mathrm{SD}=0.8)$ [32]. The participant characteristics by group are shown in Table 1 .

\section{Vegetable consumption}

At each follow-up, intervention parents consumed significantly more vegetable serves than control parents (Table 2). Effect sizes ranged from 0.36 to 0.71 serves per day (approximately 27-53 grams) [33]. Although the sensitivity analysis attenuated the effect size (0.22-0.57 serves per day), the between-group difference remained statistically significant at each follow-up (Table 3).

\section{Fruit consumption}

With the exception of 6-months, fruit consumption in the intervention group exceeded that of the control group at each follow-up, with effect sizes of 0.06-0.26 serves per day (9-39 grams) [33] (Table 2). The between-group difference remained significant when baseline values were substituted for missing values in the sensitivity analysis (0.06-0.21 serves per day) (Table 3).

\section{Discussion}

Findings suggest that a telephone-based intervention focused on changing the home food environment of preschool children can increase their parents' fruit and vegetable consumption, and that increases are sustained up to 18-months post-baseline. A systematic review found that primary prevention interventions targeting healthy adults increased combined fruit and vegetable consumption by $0.1-1.4$ serves per day [22]. The increases in consumption in this trial ranged from 0.49 to 0.97 combined 


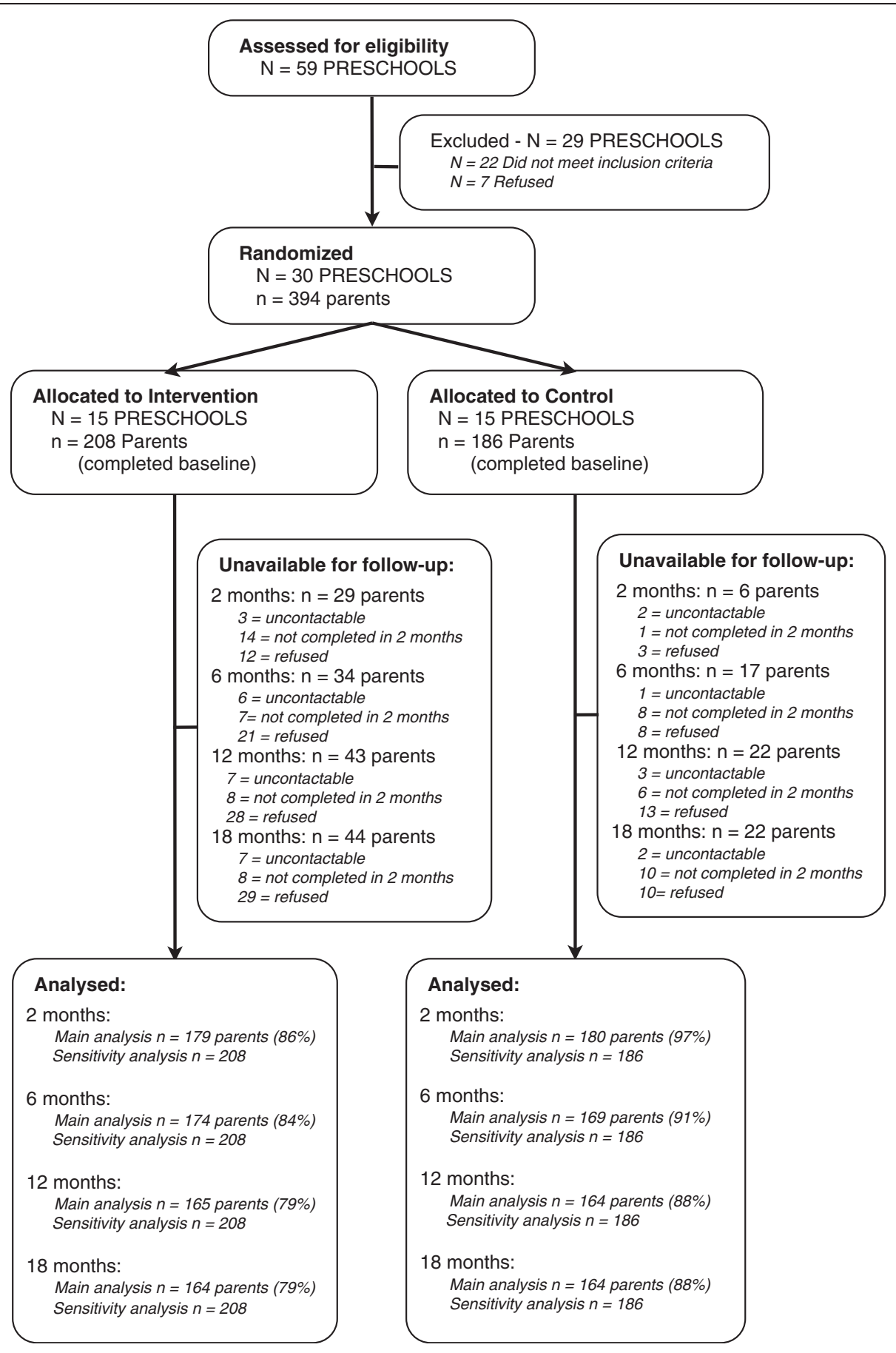

Figure 1 CONSORT flowchart.

serves per day, with an average increase of 0.7 combined serves per day, and are consistent with these review findings, and with the average increase identified in a systematic review of behavioural interventions to increase fruit and vegetable consumption (0.6 serves per day) [20]. Furthermore, these findings are consistent with other telephone-delivered interventions to increase the fruit and vegetable consumption of adults [34]. Although these reviewed trials [35-37] were of a longer duration and included a greater number of calls than the current trial, telephone interventions consisting of fewer calls have also been successful in changing behavioural outcomes [38,39]. Most notably, a trial of an intervention consisting of written materials, a written plan, and two to three telephone calls 
Table 1 Participant characteristics at baseline [15]

\begin{tabular}{lll}
\hline Participant characteristics & $\begin{array}{l}\text { Intervention } \mathbf{n}=\mathbf{2 0 8} \\
\text { mean (SD)/\% }\end{array}$ & $\begin{array}{l}\text { Control } \mathbf{n}=\mathbf{1 8 6} \\
\text { mean (SD)/\% }\end{array}$ \\
\hline Age - years & $35.2(5.6)$ & $35.7(5.0)$ \\
Gender - female & $95.2 \%$ & $96.8 \%$ \\
University Education & $45.2 \%$ & $49.5 \%$ \\
$\begin{array}{l}\text { Annual household income } \\
\text { (>AU\$100,000) }\end{array}$ & $42.4 \%$ & $40.2 \%$ \\
$\begin{array}{l}\text { Aboriginal or Torres } \\
\text { Strait Islander }\end{array}$ & $1.0 \%$ & $3.2 \%$ \\
Number of children <16 y.0. & $2.3(0.8)$ & \\
\hline
\end{tabular}

(the most comparable intervention approach) increased combined fruit and vegetable consumption by 1.4 serves per day among primary care patients after 12 weeks [40]. The magnitude of the observed effect appears to have clinical significance, with meta-analyses conducted by the World Cancer Research Fund indicating that each 50 gram increase of vegetables per day reduced the risks of stomach, oesophageal, and mouth/pharynx/larynx cancers by $15 \%$, $31 \%$ and $28 \%$ respectively [41]. This suggests that intervention approaches that target the home food environment may produce improvements in diet and reduce associated disease risks.

These significant findings are particularly noteworthy given these represent secondary trial outcomes, with the primary intervention aim being to increase preschoolers' fruit and vegetable consumption. In fact, the changes in secondary trial outcomes were sustained for longer than the primary outcome (child fruit and vegetable consumption) [16]. This may be in part due to the intervention being delivered directly to parents rather than children, and accords with the theoretical underpinnings of the intervention that changes in familial norms and behaviours are antecedent to behaviour change for children [25]. This is most clearly illustrated through the intervention strategy of role-modelling, which directly relies on changes in parents' consumption to facilitate changes in children's consumption. Furthermore, the home food environment strategies that were targeted as part of the intervention required greater input from parents. For example, although increasing the availability of fruit and vegetables in the home is associated with higher consumption among both adults and children [17-19,42], adults are required to more actively respond to this strategy through making changes in their food purchasing and food preparation behaviours. Findings from child obesity treatment studies suggest that treating parents alone may be more effective than treating the parent and child together [43]. Although results from the Healthy Habits trial suggest dietary interventions involving parents can be effective $[15,16]$, it is recommended future trials of dietary interventions investigate the relative effectiveness of strategies targeting parents-alone versus parents and children combined.

The non-significant finding for fruit consumption at 6-months reflects a slight increase in consumption of controls coinciding with a slight decrease in consumption of intervention parents. The increase in fruit consumption in the control group most likely reflects increases in the seasonal availability of fruits over the Australian summer period. This argument is strengthened by the similarly elevated fruit consumption among controls at the 18month follow-up (i.e. the summer period the following year). The decrease in fruit consumption in the intervention group may reflect the typical attenuation of effect size over time [44]. Strategies that help maintain intervention effects are important to maximise the longterm benefits of dietary interventions. The results of this trial suggest that approximately 4 to 5 months postintervention may be a critical point for the delivery of intervention maintenance strategies. However, further research is warranted.

The trial findings should be considered in conjunction with the limitations and strengths of this study. Strengths included the randomised controlled design, and standardised delivery of intervention scripts and data collection surveys. Use of self-reported, brief dietary measures may not represent optimal assessment of dietary intake and represent a limitation of the trial. More accurate assessments may result from alternative assessment methods, such as food records [45].

It is recommended that future trials investigate whether changes to the home food environment mediate changes in the fruit and vegetable consumption of children and their parents. A recent related study demonstrated that changes in child consumption of non-core foods were mediated by changes in the home food environment [46]. Identification of mediators of fruit and vegetable consumption could facilitate intervention streamlining. Beyond the cost efficiency afforded by telephone-delivery [47], this trial provides preliminary evidence of an additional efficiency; simultaneous increases in the fruit and vegetable consumption of preschool children $[15,16]$ and their parents. Interventions targeting characteristics of the home food environment therefore appear to have substantial public health utility.

\section{Conclusion}

A four-contact telephone-based intervention that focuses on changing characteristics of preschoolers' home food environment can increase parents' fruit and vegetable consumption. These results could inform the development of public health nutrition interventions attempting to improve the diet of preschoolers and their parents. 
Table 2 Changes in participant consumption of vegetables and fruit (mean daily serves) using all available data

\begin{tabular}{|c|c|c|c|c|c|c|c|c|c|c|c|c|}
\hline & \multicolumn{6}{|c|}{ Vegetable consumption (Mean daily serves) } & \multicolumn{6}{|c|}{ Fruit consumption (Mean daily serves) } \\
\hline & $\begin{array}{l}\text { Control } \\
\text { (SD) }\end{array}$ & $\begin{array}{l}\text { Control* } \\
\text { (SD) }\end{array}$ & $\begin{array}{l}\text { Intervention } \\
\text { (SD) }\end{array}$ & $\begin{array}{l}\text { Intervention* } \\
\text { (SD) }\end{array}$ & $\begin{array}{l}\text { Between group } \\
\text { difference }^{*}(95 \% \mathrm{Cl})\end{array}$ & P-value & Control (SD) & Control** (SD) $^{*}$ & $\begin{array}{l}\text { Intervention } \\
\text { (SD) }\end{array}$ & $\begin{array}{l}\text { Intervention** } \\
\text { (SD) }\end{array}$ & $\begin{array}{l}\text { Between group } \\
\text { difference } * *(95 \% \mathrm{Cl})\end{array}$ & P-value \\
\hline Baseline & $3.05(1.34)$ & - & $3.25(1.32)$ & - & - & - & $1.76(1.03)$ & - & $1.83(1.08)$ & - & - & - \\
\hline 2 mon & $3.08(1.26)$ & $3.11(0.68)$ & $3.91(1.41)$ & $3.92(0.64)$ & $0.71(0.58-0.85)$ & $<0.0001$ & $1.82(1.04)$ & $1.83(0.69)$ & $2.17(1.08)$ & $2.16(0.74)$ & $0.26(0.12-0.40)$ & 0.0003 \\
\hline 6 mon & $3.03(1.51)$ & $3.04(0.68)$ & $3.61(1.40)$ & $3.60(0.63)$ & $0.43(0.19-0.68)$ & 0.0005 & $1.95(0.97)$ & $1.96(0.61)$ & $2.04(1.08)$ & $2.04(0.63)$ & $0.06(-0.14-0.26)$ & 0.5405 \\
\hline 12 mon & $3.04(1.37)$ & $3.01(0.80)$ & $3.66(1.77)$ & $3.65(0.74)$ & $0.51(0.30-0.73$ & $<0.0001$ & $1.81(1.07)$ & $1.81(0.53)$ & $2.08(1.08)$ & $2.09(0.59)$ & $0.22(0.04-0.39)$ & 0.0153 \\
\hline $18 \mathrm{mon}$ & $3.06(1.24)$ & $3.06(0.52)$ & $3.53(1.36)$ & $3.53(0.48)$ & $0.36(0.10-0.61)$ & 0.0067 & $1.93(1.03)$ & $1.93(0.54)$ & $2.24(1.07)$ & $2.24(0.57)$ & $0.26(0.10-0.43)$ & 0.0015 \\
\hline
\end{tabular}

*Adjusted for baseline value of daily vegetable serves and clustering by preschool.

${ }^{*}$ Adjusted for baseline value of daily fruit serves and clustering by preschool. 
Table 3 Changes in participant consumption of vegetables and fruit (mean daily serves): sensitivity analysis using baseline observation carried forward

\begin{tabular}{|c|c|c|c|c|c|c|c|c|c|c|c|c|}
\hline & \multicolumn{6}{|c|}{ Vegetable consumption (Mean daily serves) } & \multicolumn{6}{|c|}{ Fruit consumption (Mean daily serves) } \\
\hline & $\begin{array}{l}\text { Control } \\
\text { (SD) }\end{array}$ & $\begin{array}{l}\text { Control* } \\
\text { (SD) }\end{array}$ & $\begin{array}{l}\text { Intervention } \\
\text { (SD) }\end{array}$ & $\begin{array}{l}\text { Intervention* } \\
\text { (SD) }\end{array}$ & $\begin{array}{l}\text { Between group } \\
\text { difference * }(95 \% \mathrm{Cl})\end{array}$ & P-value & $\begin{array}{l}\text { Control } \\
\text { (SD) }\end{array}$ & $\begin{array}{l}\text { Control** } \\
\text { (SD) }\end{array}$ & $\begin{array}{l}\text { Intervention } \\
\text { (SD) }\end{array}$ & $\begin{array}{l}\text { Intervention** } \\
\text { (SD) }\end{array}$ & $\begin{array}{l}\text { Between group } \\
\text { difference }{ }^{* *}(95 \% \mathrm{Cl})\end{array}$ & P-value \\
\hline Baseline & $3.05(1.34)$ & - & $3.25(1.32)$ & - & - & - & $1.76(1.03)$ & - & $1.83(1.08)$ & - & - & - \\
\hline 2 mon & $3.09(1.24)$ & $3.11(0.73)$ & $3.82(1.45)$ & $3.79(0.72)$ & $0.57(0.46-0.68)$ & $<0.0001$ & $1.81(1.04)$ & $1.81(0.71)$ & $2.08(1.06)$ & $2.08(0.75)$ & $0.21(0.08-0.34)$ & 0.0015 \\
\hline 6 mon & $3.11(1.49)$ & $3.10(0.78)$ & $3.56(1.44)$ & $3.54(0.76)$ & $0.32(0.11-0.53)$ & 0.0029 & $1.91(1.01)$ & $1.92(0.70)$ & $2.03(1.10)$ & $2.03(0.73)$ & $0.06(-0.11-0.23)$ & 0.4961 \\
\hline 12 mon & $3.05(1.34)$ & $3.03(0.89)$ & $3.56(1.73)$ & $3.55(0.87)$ & $0.39(0.20-0.57)$ & $<0.0001$ & $1.79(1.07)$ & $1.79(0.60)$ & 1.99 (1.04) & $2.00(0.63)$ & $0.16(0.01-0.31$ & 0.0382 \\
\hline $18 \mathrm{mon}$ & $3.11(1.24)$ & $3.11(0.69)$ & $3.44(1.41)$ & $3.43(0.68)$ & $0.22(0.01-0.43)$ & 0.0374 & $1.89(1.04)$ & $1.89(0.63)$ & $2.13(1.09)$ & $2.13(0.66)$ & $0.19(0.04-0.34)$ & 0.0139 \\
\hline
\end{tabular}

*Adjusted for baseline value of daily vegetable serves and clustering by preschool.

**Adjusted for baseline value of daily fruit serves and clustering by preschool. 


\section{Abbreviations}

InFANT: Infant feeding activity and nutrition trial; SD: Standard deviation; 95\% Cl: 95\% Confidence interval.

\section{Competing interests}

The authors declare that they have no competing interests.

\section{Authors' contributions}

LW secured grant funding. RW, LW and LB developed the intervention. KJC advised on study measures. RW and LW managed recruitment, intervention implementation and data collection. RW conducted the analysis. RW lead the drafting of the manuscript. All authors contributed to interpretation of analysis, provided critical comment on the manuscript draft and approved the final version.

\section{Acknowledgements}

The trial was funded by the Cancer Institute New South Wales (Grant Reference 08/ECF/1-18). Infrastructure support was provided by the Hunter Medical Research Institute (HMRI) and in-kind support was provided by Hunter New England Population Health. The authors would like to acknowledge the contribution of the Healthy Habits Advisory Group, the CATI interviewers, and the preschools and parent participants.

\section{Author details}

'School of Medicine and Public Health, University of Newcastle, Newcastle, NSW, Australia. ${ }^{2}$ Centre for Physical Activity \& Nutrition Research, School of Exercise \& Nutrition Sciences, Deakin University, Melbourne, VIC, Australia.

${ }^{3}$ School of Psychology, Australian Catholic University, Melbourne, VIC, Australia. ${ }^{4}$ Hunter Medical Research Institute (HMRI), Newcastle, NSW, Australia. ${ }^{5}$ Hunter New England Population Health, Locked Bag 10, Wallsend 2287NSW, Australia.

Received: 24 April 2014 Accepted: 7 November 2014

Published online: 24 December 2014

\section{References}

1. Australian Government, Department of Health and Ageing: 2007 Australian National Children's Nutrition and Physical Activity Survey - Main Findings. Canberra: The Commonwealth of Australia; 2008

2. Yngve A, Wolf A, Poortvliet E, Elmadfa I, Brug J, Ehrenblad B, Franchini B, Haraldsdottir J, Krolner R, Maes L, Perez-Rodrigo C, Sjostrom M, Thorsdottir I, Klepp K-l: Fruit and vegetable intake in a sample of 11-year-old children in 9 European Countries: The pro children cross-sectional survey. Ann Nutr Metab 2005, 49:236-245.

3. Mikkilä V, Räsänen L, Raitakari OT, Pietinen P, Viikari J: Longitudinal changes in diet from childhood into adulthood with respect to risk of cardiovascular diseases: the cardiovascular risk in young Finns study. Eur J Clin Nutr 2004, 58:1038-1045.

4. Ness AR, Maynard M, Frankel S, Davey Smith G, Frobisher C, Leary SD, Emmett PM, Gunnell D: Diet in childhood and adult cardiovascular and all cause mortality: the Boyd Orr cohort. Heart 2005, 91:894-898.

5. Maynard M, Gunnell D, Emmett P, Frankel S, Davey Smith G: Fruit, vegetables, and antioxidants in childhood and risk of adult cancer: the Boyd Orr cohort. J Epidemiol Community Health 2003, 57:218-225.

6. Promoting Fruit and Vegetable Consumption Around the World. (Information Sheet) [http://www.who.int/dietphysicalactivity/fruit/en/index2.html]

7. Rosenkranz RR, Dzewaltowski DA: Model of the home food environment pertaining to childhood obesity. Nut Rev 2008, 66:123-140.

8. Wansink B: Nutritional gatekeepers and the $72 \%$ solution. J Am Diet Assoc 2006, 106:1324-1327.

9. Hearn MD, Baranowski T, Baranowski J, Doyle C, Smith M, Lin LS, Resnicow K: Environmental influences on dietary behavior among children: availability and accessibility of fruits and vegetables enable consumption. J Health Educ 1998, 29:26-32.

10. Tibbs T, Haire-Joshu D, Schechtman KB, Brownson RC, Nanney MS, Houston C, Auslander W: The relationship between parental modeling, eating patterns, and dietary intake among African-American parents. J Am Diet Assoc 2001, 101:535-541.

11. Birch LL: Development of food preferences. Annu Rev Nutr 1999, 19:41-62.

12. Wolfenden L, Wyse RJ, Britton BI, Campbell KJ, Hodder RK, Stacey FG, McElduff $P$, James EL: Interventions for increasing fruit and vegetable consumption in children aged 5 years and under. Cochrane Database Syst Rev 2012, 11.

13. Haire-Joshu D, Elliott MB, Caito NM, Hessler K, Nanney MS, Hale N, Boehmer TK, Kreuter M, Brownson RC: High 5 for Kids: the impact of a home visiting program on fruit and vegetable intake of parents and their preschool children. Prev Med 2008, 47:77-82.

14. Lioret S, Campbell KJ, Crawford D, Spence AC, Hesketh K, McNaughton SA: A parent focused child obesity prevention intervention improves some mother obesity risk behaviors: the Melbourne inFANT program. Int J Behav Nutr Phys Act 2012, 9:100.

15. Wyse RJ, Wolfenden L, Campbell E, Campbell KJ, Wiggers J, Brennan L, Fletcher A, Bowman J, Heard TR: A cluster randomized controlled trial of a telephone-based parent intervention to increase preschoolers' fruit and vegetable consumption. Am J Clin Nutr 2012, 96:102-110.

16. Wolfenden L, Wyse RJ, Campbell E, Brennan L, Campbell KJ, Fletcher A, Wiggers J, Bowman J, Heard TR: Randomized controlled trial of a telephone-based intervention for child fruit and vegetable intake: long-term follow-up. Am J Clin Nutr 2014, 99:543-550.

17. Rasmussen M, Krølner R, Klepp K-I, Lytle L, Brug J, Bere E, Due P: Determinants of fruit and vegetable consumption among children and adolescents: a review of the literature. part I: quantitative studies. Int J Behav Nutr Phys Act 2006, 3:22

18. Pearson N, Biddle S, Gorely T: Family correlates of fruit and vegetable consumption in children and adolescents: a systematic review. Public Health Nutr 2009, 12:267-283.

19. van der Horst K, Oenema A, Ferreira I, Wendel-Vos W, Giskes K, van Lenthe F, Brug J: A systematic review of environmental correlates of obesity-related dietary behaviors in youth. Health Educ Res 2007, 22:203-226.

20. Ammerman AS, Lindquist CH, Lohr KN, Hersey J: The efficacy of behavioral interventions to modify dietary Fat and fruit and vegetable intake: a review of the evidence. Prev Med 2002, 35:25-41.

21. Thomson CA, Ravia J: A systematic review of behavioral interventions to promote intake of fruit and vegetables. J Am Diet Assoc 2011, 111:1523-1535.

22. Pomerleau J, Lock K, Knai C, McKee M: Effectiveness of interventions and programmes promoting fruit and vegetable consumption. J Nutr 2005, 135:2486-2495.

23. Story M, Kaphingst KM, Robinson-O'Brien R, Glanz K: Creating healthy food and eating environments: policy and environmental approaches. Annu Rev Public Health 2008, 29:253-272.

24. Wyse RJ, Wolfenden L, Campbell E, Brennan L, Campbell KJ, Fletcher A, Bowman J, Heard TR, Wiggers J: A cluster randomised trial of a telephone-based intervention for parents to increase fruit and vegetable consumption in their 3- to 5-year-old children: study protocol. BMC Public Health 2010, 10:216.

25. Golan M, Weizman A: Familial approach to the treatment of childhood obesity: conceptual model. J Nutr Educ 2001, 33:102-107.

26. Wyse RJ, Wolfenden L, Campbell E, Campbell K, Brennan L, Fletcher A, Bowman J, Heard T, Wiggers J: A pilot study of a telephone-based parental intervention to increase fruit and vegetable consumption in 3-5-year-old children. Public Health Nutr 2011, 14:2245-2253.

27. Abraham C, Michie S: A taxonomy of behavior change techniques used in interventions. Health Psychol 2008, 27:379-387.

28. Coalfields Healthy Heartbeat: Healthy Budget Bites: Healthy Eating on a Budget. Hunter New England Health; 2007.

29. Australian Government, Department of Health and Ageing: The Australian Guide to Healthy Eating - Background Information for Consumers. Canberra: The Commonwealth Government of Australia; 2009.

30. Australian Bureau of Statistics: National Nutrition Survey: Users' Guide. Canberra: Department of Health and Family Services; 1998.

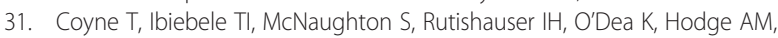
McClintock C, Findlay MG, Lee A: Evaluation of brief dietary questions to estimate vegetable and fruit consumption - using serum carotenoids and red-cell folate. Public Health Nutr 2005, 8:298-308.

32. Wyse RJ, Campbell E, Nathan N, Wolfenden L: Associations between characteristics of the home food environment and fruit and vegetable intake in preschool children: a cross-sectional study. BMC Public Health 2011, 11:938.

33. National Health \& Medical Research Council: Eat For Health: Australian Dietary Guidelines - Summary. Canberra: The Commonwealth Government of Australia; 2013. 
34. Eakin EG, Lawler SP, Vandelanotte C, Owen N: Telephone interventions for physical activity and dietary behavior change. Am J Prev Med 2007, 32:419-434.

35. Pakiz B, Flatt SW, Mills KC, Jordan LJ, Carethers JM, Rock CL: Quality of life and diet intervention in individuals at risk for recurrence of colorectal adenomas. Psychooncology 2005, 14:85-93.

36. Delichatsios HK, Friedman RH, Glanz K, Tennstedt S, Smigelski C, Pinto BM, Kelley $\mathrm{H}$, Gillman MW: Randomized trial of a "talking computer" to improve adults' eating habits. Am J Health Promot 2001, 15:215-224.

37. Pierce JP, Newman VA, Flatt SW, Faerber S, Rock CL, Natarajan L, Caan BJ, Gold EB, Hollenbach KA, Wasserman L, Jones L, Ritenbaugh C, Stefanick ML, Thomson CA, Kealey S, Women's Healthy Eating and Living (WHEL) Study Group: Telephone counseling intervention increases intakes of micronutrient- and phytochemical-rich vegetables, fruit and fiber in breast cancer survivors. J Nutr 2004, 134:452-458.

38. Green BB, McAfee T, Hindmarsh M, Madsen L, Caplow M, Buist D: Effectiveness of telephone support in increasing physical activity levels in primary care patients. Am J Prev Med 2002, 22:177-183.

39. Elley CR, Kerse N, Arroll B, Robinson E: Effectiveness of counselling patients on physical activity in general practice: cluster randomised controlled trial. BMJ 2003, 326:793-793.

40. Djuric Z, Ellsworth JS, Ren J, Sen A, Ruffin MT: A randomized feasibility trial of brief telephone counseling to increase fruit and vegetable intakes. Prev Med 2010, 50:265-271.

41. World Cancer Research Fund/American Institute for Cancer Research: Food, Nutrition, Physical Activity, and the Prevention of Cancer:a Global Perspective. Washington DC: American Institute for Cancer Research; 2007.

42. Kamphuis C, Giskes K, de Bruijn GJ: Environmental determinants of fruit and vegetable consumption among adults: a systematic review. Br J Nutr 2006, 96:620-635.

43. Golan M, Kaufman V: Childhood obesity treatment: targeting parents exclusively v. parents and children. Br J Nutr 2006, 95:1008-1015.

44. Fjeldsoe B, Neuhaus M, Winkler E, Eakin E: Systematic review of maintenance of behavior change following physical activity and dietary interventions. Health Psychol 2011, 30:99-109.

45. Thompson FE, Subar AF: Dietary assessment methodology. In Nutrition in the Prevention and Treatment of Disease. Edited by Coulston A, Boushey C, Burlington MA. MA: Elsevier Academic Press; 2008:3-39.

46. Fletcher A, Wolfenden $\mathrm{L}$, Wyse RJ: A randomised controlled trial and mediation analysis of the "Healthy Habits", telephone-based dietary intervention for preschool children. Int J Behav Nutr Phys Act 2013, 10:43

47. Graves N, Barnett AG, Halton KA, Veerman JL, Winkler E, Owen N, Reeves MM, Marshall A, Eakin E: Cost-effectiveness of a telephone-delivered intervention for physical activity and diet. PLOS ONE 2009, 4:e7135.

\section{Submit your next manuscript to BioMed Central and take full advantage of:}

- Convenient online submission

- Thorough peer review

- No space constraints or color figure charges

- Immediate publication on acceptance

- Inclusion in PubMed, CAS, Scopus and Google Scholar

- Research which is freely available for redistribution 